\title{
ESTUDO COMPARATIVO ENTRE AGROTÊXTIL E INSETICIDAS NO CONTROLE DA MOSCA MINADORA DA BATATA
}

\author{
Comparative study between nonwoven and insecticides \\ to control the potato leaf miner fly
}

\author{
Rui Scaramella Furiatti', Airton Rodrigues Pinto Junior ${ }^{2}$, João Acir Batista Lopes ${ }^{3}$ \\ ${ }^{1}$ Engenheiro Agrônomo. Professor Dr. do Departamento de Fitotecnia e Fitossanidade do Curso de Agronomia da UEPG. \\ Ponta Grossa, PR - Brasil. e-mail: furiatti@myzus.com.br \\ ${ }^{2}$ Engenheiro Agrônomo. Professor Dr. do Curso de Agronomia da Pontifícia Universidade Católica do Paraná. Curitiba, PR - \\ Brasil.e-mail: airton.junior@pucpr.br \\ ${ }^{3}$ Engenheiro Agrônomo, M. Sc. Curso de Agronomia da UEPG. Ponta Grossa, PR - Brasil. e-mail: furiatti@myzus.com.br
}

\begin{abstract}
Resumo
Na cultura da batata, a mosca minadora (Liriomyza huidobrensis) é uma das pragas mais nocivas, afetando drasticamente a produção. Produtos de controle alternativo, como o agrotêxtil, são desejáveis, funcionando como barreira física para a praga. O objetivo deste trabalho foi comparar o uso do agrotêxtil e de inseticida para controlar a mosca L. huidobrensis em plantas de batata. Foram realizados cinco tratamentos: testemunha (T1); inseticida (T2); agrotêxtil (T3); agrotêxtil + inseticida (T4); agrotêxtil + inseticida, descobrindo as plantas no momento da pulverização (T5). O delineamento experimental utilizado foi em blocos inteiramente casualizados, com quatro repetições. O inseticida utilizado foi a cyromazine 700 PM na dose de 120 g.ha ${ }^{-1}$, em aplicações quinzenais. Pode-se observar por meio dos resultados que a população da praga diminuiu no decorrer do tempo e que essa prefere atacar inicialmente as folhas do extrato inferior das plantas, passando para os demais extratos. $\mathrm{O}$ uso do agrotêxtil diminuiu o índice de infestação, sendo que todos os tratamentos sob cultivo protegido diferiram estatisticamente dos tratamentos em campo aberto. Cyromazine não foi eficiente no controle da mosca minadora, o que pode estar relacionado com a pulverização ineficiente, intervalos de aplicação inadequados, ausência de adulticida e seleção de indivíduos resistentes. A produtividade foi inferior em todos os tratamentos que utilizaram o agrotêxtil. O agrotêxtil, utilizado sozinho, foi eficaz contra a mosca minadora, podendo ser reduzido o número de aplicações de inseticidas e a contaminação ambiental por eles causada.
\end{abstract}

Palavras-chave: Batata; Agrotêxtil; Liriomyza buidobrensis; Cyromazine. 


\begin{abstract}
The leaf miner fly (Liriomyza huidobrensis) is one of the noxious pest that decreases drastically potato crops yield. Alternative control methods, like nonwoven, are desired, because they work as a physical barrier to the pest. The aim of this work was to compare nonwoven and insecticides to control the fly L. huidobrensis in potato plants. Five treatments were conducted: control (T1); insecticide (T2); nonwoven (T3); nonwoven + insecticide (T4); nonwoven + insecticide, uncovering plants at spraying moment (T5). The used experimental design was randomized blocks, with 4 replications. The used insecticide was cyromazine 700 PM, dosage $120 \mathrm{~g} . \mathrm{ha}^{-1}$, with applications every 15 days. Results showed that pest population decreases during time, and it prefers to attack initially the leaves of the plant's under portion, spreading after to other parts. The use of nonwoven decreases the infestation index, consequently all treatments under protected cultivation were statistically different from treatments without cover. Cyromazine was not efficient on the leaf miner fly control, what might be related to an inefficient spraying, inadequate spraying interval, adulticide absence and selection of resistant individuals. However, yield was inferior in all treatments that used nonwoven. The nonwoven, used alone, was efficient against the leaf miner fly, what could possibly decrease the necessity of insecticide application and reduces its environmental contamination.
\end{abstract}

Keywords: Potato; Nonwoven; Liriomyza huidobrensis; Cyromazine.

\title{
INTRODUÇÃO
}

Dos vários fatores que contribuem para diminuir a produtividade da batata, as pragas figuram como um dos principais, pois essa cultura é atacada por diversos insetos desde seu plantio até a colheita e armazenamento. Dentre as pragas de maior importância econômica, destaca-se a mosca Liriomyza buidobrensis (Blanchard, 1926) (Diptera: Agromyzidae), a qual é conhecida vulgarmente como "mosca minadora", "larva minadora" ou "minador das folhas" (CRUZ, 1988).

Segundo Cruz (1988) e Reis e Souza (1999), as larvas deste inseto podem causar danos expressivos à cultura, ao se alimentarem e minarem as folhas das plantas. As minas, ou lesões necróticas, encontradas principalmente na região da nervura central dos folíolos, diminuem a área foliar e conseqüentemente a capacidade fotossintética da planta, podendo também ocasionar murcha e seca das folhas, bem como favorecer a entrada de agentes fitopatogênicos importantes.

Técnicas para o manejo adequado deste inseto devem ser desenvolvidas e merecem atenção especial. O agrotêxtil é confeccionado a partir de filamentos de polipropileno muito finos, unidos entre si por um processo térmico de solda. Esta termosoldadura dos filamentos forma um manto leve, poroso, com resistência suficiente para ser usado na agricultura. Pode ser colocado diretamente sobre as culturas, sem a necessidade do uso de nenhuma estrutura de apoio, logo após o transplante ou plantio, sendo que a planta levanta o agrotêxtil conforme seu crescimento (ABINT, 1999).

Diversos autores citam como vantagens da utilização do agrotêxtil no cultivo protegido: modificação do período de cultivo, adiantando ou atrasando-o, com aumento da precocidade e produção; proteção do solo e da cultura contra danos causados por chuvas de granizo; aumento da porcentagem de germinação das sementes; aumento da temperatura do ar e do solo, conservação da umidade do solo, favorecendo os processos de desnitrificação e beneficiando a disponibilidade e absorção de nitrogênio pela planta (SÁ, 1998); melhor enraizamento de rizomas (REGHIN; OTTO; SILVA, 2000); proteção contra geadas (OTTO et al., 2000b); prevenção ou redução do ataque de insetos e outras pragas, principalmente os transmissores de vírus (WELLS; LOY, 1985; GREGORIE, 1992; HEMPHILL JR. et al., 1988). 
Sá (1998) cita como desvantagens do método a fragilidade do material, que exige maior cuidado no manuseio; comparando ao cultivo em ambiente natural. Esta técnica aumenta a mão-deobra, pois é necessária a retirada da proteção de agrotêxtil para a execução de algumas práticas culturais; favorece o crescimento das plantas daninhas sob a proteção, aumentando o número de capinas e/ou a necessidade da utilização de herbicidas na fase inicial da cultura.

O presente trabalho teve como objetivo um estudo comparativo entre agrotêxtil e inseticidas no controle da mosca minadora L. buidobrensis na cultura da batata.

\section{MATERIAL E MÉTODOS}

O experimento foi conduzido na Fazenda Escola "Capão da Onça" da Universidade Estadual de Ponta Grossa - PR, situada na latitude 2505' Sul e longitude 50³3' Oeste de Greenwich, em solo Cambissolo Háplico Típico, em área ainda não cultivada com batata.

Realizou-se o plantio no dia 02 de novembro utilizando a cultivar bintje. A adubação de base constou de 2,5 ton.ha ${ }^{-1}$ da formulação 2-20-20, com cobertura de $132 \mathrm{~kg}$ de $\mathrm{N}$ (na forma de uréia) trinta dias após a emergência. Os tubérculos foram plantados com $0,30 \mathrm{~m}$ entre si e 0,75 m entre linhas. A amontoa ocorreu logo após o plantio.

Os tratamentos constaram basicamente do uso do agrotêxtil em comparação à cultura descoberta e do uso ou não de inseticidas, tanto nos tratamentos que receberam cobertura e os descobertos, como se segue:

Tratamento 1 - Testemunha; Tratamento 2 - Inseticida; Tratamento 3 - Agrotêxtil; Tratamento 4 - Agrotêxtil + inseticida; Tratamento 5 - Agrotêxtil + inseticida, descobrindo a cultura no momento da aplicação do inseticida.

O agrotêxtil utilizado tinha 1,60 $\mathrm{m}$ de largura e densidade de $20 \mathrm{~g} \mathrm{~m}^{-2}$, sendo fixado, logo após a emergência das plantas - nas duas linhas de bordadura das parcelas -, por terra em um lado e através de ganchos de metal no outro. As parcelas foram constituídas por três linhas de quatro metros de comprimento.

O controle da mosca minadora foi efetuado com aplicações quinzenais de cyromazine 700 PM, na dosagem de $120 \mathrm{~g} \mathrm{ha}^{-1}$, a partir da aparição das primeiras puncturas. Para o controle de doenças, foram realizadas pulverizações com fungicidas registrados e regularmente empregados, dependendo da incidência da doença e das condições climáticas.

O delineamento experimental adotado foi de blocos casualizados, com cinco tratamentos e quatro repetições.

Os danos causados pelas larvas da mosca minadora foram avaliados em três folíolos apicais de folhas de batata, em cada extrato da planta (superior, médio e inferior, distinguidos pela idade da folha), em sete plantas por parcela, totalizando 63 folíolos por parcela. Tanto as folhas nos diferentes extratos, quanto as plantas eram escolhidas ao acaso dentro da parcela. Para as avaliações foram consideradas apenas as minas jovens. De acordo com a área lesionada, atribuíram-se notas, utilizando-se a escala:

Nota 0 - Folíolo sem lesão; Nota 1 - 1 a 25\% de área foliar lesionada; Nota 2- 26 a 50\% de área foliar lesionada; Nota 3- 51 a 75\% de área foliar lesionada; Nota 4- 76 a 100\% de área foliar lesionada.

As avaliações começaram após o início do aparecimento das minas, sendo realizadas nos dias 04, 11 e 18 de janeiro, aos 48, 55 e 62 dias após emergência (DAE) das plantas de batata. As notas obtidas nas avaliações foram transformadas em índice de ataque na planta pela fórmula de TOWNSENDHEUBERGUER, descrita abaixo:

$$
\% \text { infestação }=\frac{\sum(n \cdot V)}{i . N} \cdot 100
$$

Onde:

V: Valor da nota;

i: Valor da nota mais alta;

n: Número de folíolos avaliados;

N: Total de folíolos avaliados. 
A colheita foi realizada no dia 08 de fevereiro (83 DAE), manualmente, sendo colhidas apenas as duas linhas da bordadura de todas as parcelas. Após a colheita, estimou-se a produção por parcela por meio da pesagem dos tubérculos e também o rendimento em $\mathrm{kg} \cdot \mathrm{ha}^{-1}$. O número de hastes e tubérculos.ha ${ }^{-1}$ também foi estimado. O peso médio de tubérculos foi obtido pela divisão do rendimento na parcela pelo número de tubérculos colhidos nela.

Para o cálculo de custo por tonelada de batata dos tratamentos, utilizou-se o custo básico para produção de um hectare de batata da região de Castro, PR, do qual se retirou o custo dos inseticidas, sendo acrescido a ele o custo dos inseticidas utilizados nos experimentos, dependendo do tratamento.

Os resultados foram submetidos à análise de variância (ANOVA) e as diferenças entre as médias, quando significativas, testadas pelo teste de Tukey, a 5\% de probabilidade.

\section{RESULTADOS E DISCUSSÃO}

Foram realizadas três avaliações no decorrido experimento.

TABELA 1 - Índice de dano de Liriomyza huidobrensis nos extratos foliares, em três momentos, Ponta Grossa, PR, 2001

Table 1 - Damage rate of Liriomyza huidobrensis in plants portions, in three moments, Ponta Grossa, PR, 2001

\begin{tabular}{lllll}
\hline Extrato & \multicolumn{3}{c}{ Época de avaliação } & Média \\
\hline & $48 \mathrm{DAE}$ & $55 \mathrm{DAE}$ & $62 \mathrm{DAE}$ \\
\hline Superior & $0,07 \mathrm{~A} \mathrm{c}$ & $0,00 \mathrm{~A} \mathrm{~b}$ & $0,16 \mathrm{~A} \mathrm{~b}$ & $0,08 \mathrm{c}$ \\
Médio & $2,37 \mathrm{~A} \mathrm{~b}$ & $0,36 \mathrm{~B} \mathrm{~b}$ & $0,38 \mathrm{~B} \mathrm{~b}$ & $0,94 \mathrm{~b}$ \\
Inferior & $9,03 \mathrm{Aa}$ & $3,44 \mathrm{Ba}$ & $3,21 \mathrm{Ba}$ & $4,96 \mathrm{a}$ \\
Média & $3,05 \mathrm{~A}$ & $1,03 \mathrm{~B}$ & $1,06 \mathrm{~B}$ & - \\
\hline C.V. & 33,03 \\
\hline
\end{tabular}

Médias seguidas pela mesma letra maiúscula na horizontal ou seguidas da mesma letra minúscula na vertical não diferem entre si pelo teste de Tukey a $5 \%$.

Na primeira época de avaliação, observou-se diferença na incidência de L. huidobrensis nos três extratos avaliados, porém, a partir da segunda avaliação, não houve diferença entre o extrato médio e o superior, embora a média geral tenha apontado diferenças marcantes entre os extratos. Nesse período, houve diminuição na infestação nos extratos inferior e médio (TABELA 1). Observa-se também que as fêmeas da mosca preferem ovipositar inicialmente no extrato inferior da planta, atingindo os demais extratos posteriormente.

$\mathrm{Na}$ Tabela 2 constata-se, pelo índice de infestação, que a população de L. buidobrensis diminuiu no decorrer do experimento, provavelmente, devido às condições climáticas não favoráveis ao inseto ocorridas no período das avaliações. Aos $48 \mathrm{DAE}$, os tratamentos em campo aberto apresentaram maior dano pelo inseto que os tratamentos que receberam a proteção do agrotêxtil, embora o uso de agrotêxtil associado ao inseticida não diferiu da testemunha, contrariando os resultados observados nos demais tratamentos que utilizaram agrotêxtil. Aos $55 \mathrm{DAE}$ e aos $62 \mathrm{DAE}$ observou-se que o uso de inseticida na parte aérea não diferiu dos tratamentos que utilizaram o agrotêxtil, porém também não diferiu da testemunha. Aos $62 \mathrm{DAE}$, os tratamentos que utilizaram agrotêxtil e inseticida (T4 e T5) não diferiram da testemunha, a qual não diferiu do tratamento que utilizou apenas inseticida. Pode-se observar, nas três épocas, que a retirada da cobertura no momento da aplicação não interferiu na eficácia da aplicação do inseticida e que os tratamentos com agrotêxtil resultaram em menor infestação de L. huidobrensis. 
TABELA 2 - Índice de dano de Liriomyza buidobrensis, em três momentos, Ponta Grossa, PR, 2001

Table 2 - Damage rate of Liriomyza huidobrensis in three moments, Ponta Grossa, PR, 2001

\begin{tabular}{|c|c|c|c|c|}
\hline \multirow[t]{2}{*}{ Extrato } & \multicolumn{3}{|c|}{ Época de avaliação } & \multirow[t]{2}{*}{ Média } \\
\hline & $48 \mathrm{DAE}$ & $55 \mathrm{DAE}$ & $62 \mathrm{DAE}$ & \\
\hline Testemunha & 4,16 Aab & $2,51 \mathrm{Aa}$ & $2,54 \mathrm{Aa}$ & $3,04 \mathrm{a}$ \\
\hline Inseticida & 6,61 Aa & 1,89 Bab & $0,99 \mathrm{Bab}$ & $2,83 \mathrm{a}$ \\
\hline Agrotêxtil & 1,63 A c & $0,29 \mathrm{~A} \mathrm{~b}$ & $0,42 \mathrm{~A} B$ & $0,73 \mathrm{~b}$ \\
\hline $\begin{array}{l}\text { Agrotêxtil + } \\
\text { Inseticida }\end{array}$ & $2,13 \mathrm{~A} \mathrm{bc}$ & $0,50 \mathrm{~B} \mathrm{~b}$ & $0,72 \mathrm{ABab}$ & $1,06 \mathrm{~b}$ \\
\hline $\begin{array}{l}\text { Agrot. + Inset., } \\
\text { descobrindo a } \\
\text { cultura }\end{array}$ & 1,69 A & $0,41 \mathrm{~A} \mathrm{~b}$ & 0,91 Aab & $0,97 \mathrm{~b}$ \\
\hline Média & $3,05 \mathrm{~A}$ & $1,03 \mathrm{~B}$ & $1,06 \mathrm{~B}$ & - \\
\hline C.V. & & 33,03 & & \\
\hline
\end{tabular}

Médias seguidas pela mesma letra minúscula na vertical ou pela mesma letra maiúscula na horizontal não diferem pelo teste de Tukey a $5 \%$.

TABELA 3 - Índice de dano de Liriomyza buidobrensis nos tratamentos, nos extratos foliares de planta de batata, Ponta Grossa, PR, 2001

Table 3 - Damage rate of Liriomyza huidobrensis in the treatments, in the potato plant portions, Ponta Grossa, PR, 2001

\begin{tabular}{lllll}
\hline Tratamento & \multicolumn{3}{c}{ Extrato } & Média \\
\hline & Superior & Médio & Inferior & \\
\hline & & $1,65 \mathrm{Bab}$ & $10,33 \mathrm{Aa}$ & $3,04 \mathrm{a}$ \\
Testemunha & $0,07 \mathrm{Ca}$ & $2,67 \mathrm{Ba}$ & $7,37 \mathrm{Aa}$ & $2,83 \mathrm{a}$ \\
Inseticida & $0,13 \mathrm{Ca}$ & $0,07 \mathrm{~B} \mathrm{~b}$ & $2,44 \mathrm{~A} \mathrm{~B}$ & $0,73 \mathrm{~b}$ \\
Agrotêxtil & $0,13 \mathrm{Ba}$ & $0,60 \mathrm{~B} \mathrm{~b}$ & $3,16 \mathrm{~A} \mathrm{~b}$ & $1,06 \mathrm{~b}$ \\
$\begin{array}{l}\text { Agrotêxtil }+ \\
\text { Inseticida }\end{array}$ & $0,00 \mathrm{Ba}$ & $0,26 \mathrm{~B} \mathrm{~b}$ & $3,22 \mathrm{~A} \mathrm{~b}$ & $0,97 \mathrm{~b}$ \\
$\begin{array}{l}\text { Agrot. + Inset., } \\
\text { descobrindo a } \\
\text { cultura }\end{array}$ & & & \\
Média & $0,07 \mathrm{Ba}$ & $0,94 \mathrm{~B}$ & $4,96 \mathrm{~A}$ & - \\
\hline C.V. & 33,03 & \\
\hline
\end{tabular}

Médias seguidas pela mesma letra minúscula na vertical ou pela mesma letra maiúscula na horizontal não diferem entre si pelo teste de Tukey a $5 \%$. 
Não houve diferença entre os tratamentos no extrato superior, porém, no extrato médio, o uso de inseticida foi inferior aos tratamentos que utilizaram a cobertura, e nenhum dos tratamentos diferiu da testemunha (TABELA 3). No extrato inferior, onde a incidência do inseto foi maior, a proteção das plantas com agrotêxtil reduziu significativamente a infestação pela praga, discriminando os tratamentos com mais precisão.

$\mathrm{Na}$ Tabela 2 e Tabela 3, por meio da média geral, observou-se que o agrotêxtil reduziu a infestação pela mosca, quando comparado ao cultivo em campo aberto, porém é notória a semelhança entre os tratamentos que receberam o agrotêxtil e entre aqueles que não o receberam. Conclui-se que o inseticida cyromazine não mostrou a eficácia esperada, considerando que não diferiu da testemunha.

$\mathrm{O}$ índice de infestação observado sob o cultivo protegido pode estar relacionado à sua largura, a qual pode ter sido maior, e aos dispositivos utilizados para a sua fixação no solo. A entrada de insetos pode ter ocorrido em pontos onde a cobertura não foi perfeita.

Para o quesito rendimento, pode-se observar que a cultura respondeu negativamente ao uso do agrotêxtil. $\mathrm{O}$ aumento da área foliar da planta sob o agrotêxtil pode ter afetado o rendimento, no entanto não houve diferença significativa no número de ramas e de tubérculos entre a testemunha e o tratamento que recebeu apenas o agrotêxtil (tratamentos 1 e 3 , respectivamente). Porém, de modo geral, o número de tubérculos e a massa média foram maiores nos tratamentos desprotegidos do agrotêxtil, incluindo a testemunha (TABELA 4). Dessa forma, o agrotêxtil pode ser utilizado na multiplicação de batata-semente, onde o produtor visa maior número de tubérculos/área.

TABELA 4 - Número de hastes e tubérculos e peso médio de tubérculos, Ponta Grossa, PR, 2001

Table 4 - Number of stem and tuber and tuber average weight, Ponta Grossa, PR, 2001

\begin{tabular}{|c|c|c|c|}
\hline Tratamentos & n. ${ }^{o}$ Ramas.ha ${ }^{-1}$ & n. ${ }^{o}$ Tubérculos ha-1 & Massa média de tubérculos (g) \\
\hline Testemunha & $58333,32 \mathrm{~b}$ & 366249,86 & $61,31 \mathrm{ab}$ \\
\hline Inseticida & $79999,98 \mathrm{a}$ & 382083,19 & $74,74 \mathrm{a}$ \\
\hline Agrotêxtil & $67499,98 \mathrm{ab}$ & 314166,58 & $53,54 \mathrm{ab}$ \\
\hline Agrotêxtil+inseticida & $72083,32 \mathrm{ab}$ & 334583,24 & $52,50 \mathrm{~b}$ \\
\hline Agrot. + inset., descobrindo a cultura & 81249,98 a & 312916,59 & $52,17 \mathrm{~b}$ \\
\hline C.V. $\%$ & 12,32 & 12,42 & 16,66 \\
\hline
\end{tabular}

Médias seguidas pela mesma letra na vertical não diferem entre si pelo teste de Tukey a $5 \%$.

O tratamento que utilizou inseticida, sem agrotêxtil, obteve a maior massa média de tubérculos, talvez ocasionado pela proteção contra outros insetos e/ou doenças associadas a eles.

A redução de rendimento nos tratamentos sob o agrotêxtil pode estar ligada ao crescimento acelerado e abundante das folhagens e ramas, o que pode ter retardado o crescimento dos tubérculos.

Outro fator que pode explicar o rendimento inferior de tubérculos sob o agrotêxtil seria a temperatura. Couto (1978) afirma que as condições de clima que facilitam a vegetação abundante das plantas podem ser prejudiciais à formação de tubérculos. O autor cita que altas temperaturas são prejudiciais à cultura, porém Otto, Gimenez e Castilla (2000a) relataram que sob o agrotêxtil, durante o desenvolvimento das culturas, as temperaturas são iguais ou menores que as observadas no meio externo.

Segundo Parrella (1987), a falha no controle químico da mosca minadora pode estar relacionada à diminuição da ação de inimigos naturais na área tratada, ou ao estímulo provocado por doses subletais do inseticida no adulto, ou a seleção de indivíduos resistentes na área. As subdoses ocorrem principalmente nas folhas inferiores da planta, devido à ineficiência na aplicação do inseticida, fato agravado pela preferência da mosca minadora em ovipositar nas folhas inferiores das plantas de batata, como foi mostrado na Tabela 1. Porém, como a cyromazine é um regulador de crescimento sistêmico com pequena ação sobre inimigos naturais, a falha de controle nesse experimento pode estar ligada à qualidade da pulverização, ao intervalo de aplicação inadequado, presença de população resistente ou ainda à ausência de um adulticida. 
Argumentos que reforçam essas conclusões vêm de trabalhos que demonstram a eficácia de cyromazine no controle de L. huidobrensis. Pereira et al. (1998) concluíram que, entre outros tratamentos, a cyromazine 750 PM (120 g.ha $\left.{ }^{-1}\right)$ (2 aplicações) foi eficaz no controle desse inseto. Fagundes (2000) estudou o efeito de inseticidas aplicados em diferentes épocas no número de puncturas de L. huidobrensis na cultura da batata, concluindo que na variedade Atlantic, sob baixa pressão populacional da mosca minadora, destacam-se os tratamentos à base de cyromazine, quando aplicado preventivamente, e abamectin, aplicado curativamente.

Não há na literatura trabalhos visando o controle de L. huidobrensis através de agrotêxtil, porém há citações de sua eficácia contra outros insetos. Webb e Linda (1992) citam que o uso do agrotêxtil, tanto sozinho, quanto associado com "mulch" de polietileno branco e preto, evitou o dano de Diaphania nitidalis, Diaphania byalinata, Bemisia tabaci e diversas espécies de afídeos em abobrinha, no cultivo de outono na Flórida.

Segundo Hata et al. (1995), o uso do agrotêxtil em flores de gengibre reduziu significativamente a infestação das formigas Pheidole megacephala e Technomyrmes albipes e o afídeo Pentalonia nigronervosa. Segundo esses autores, uma simples aplicação foliar do inseticida clorpiriphos, antes de cobrir as flores, reduziu significativamente a porcentagem de infestação pelas formigas, $P$. nigronervosa, Aphis gossypii e Sciothrips cardamomi.

Os resultados deste trabalho de pesquisa concordam com Souza (1997), o qual trabalhou com a flutuação populacional da mosca minadora e seus danos em batata, no sul de Minas Gerais.

São necessários novos estudos visando elucidar as causas da redução no rendimento da cultivar de batata bintje cultivada sob o agrotêxtil, considerando que o uso da cobertura pode contribuir na produção de batata-semente de alta qualidade, com custos baixos, e redução na contaminação ambiental por pesticidas.

\section{CONCLUSÕES}

Conclui-se que o agrotêxtil é um eficiente método de proteção contra a L. huidobrensis sem o uso de inseticidas.

O agrotêxtil, utilizado sozinho, foi estatisticamente significante e superior ao uso de inseticidas no controle da larva da mosca minadora.

\section{REFERÊNCIAS}

ABINT. Associação Brasileira das Indústrias de Não Tecidos. Agrotêxtil: Uma nova alternativa de proteção para a agricultura. São Paulo: ABINT, 1999. 3 p. Disponível em: <http:// www.abint.org.br/manual-agrotextil-2.htm>. Acesso em: 25 maio 2007.

COUTO, F. A. A. Efeito da temperatura e do comprimento do dia. Viçosa, Universidade Rural do Estado de Minas Gerais, 1960. In: COUTO, F. A. A. ed. Batatinha. Brasília: Embrapa. 1978. v. 1. (Resumos informativos).

CRUZ, C. A. Observações sobre o comportamento de Liriomyza buidobrensis Blanchard, 1926 (Diptera: Agromyzidae) em cultura de batatinha (Solanum tuberosum L.). 123 f.. Dissertação (Mestrado em Ciências Biológicas) - Escola Superior de Agricultura Luiz de Queiroz/ USP, Piracicaba, 1988.

FAGUNDES, R. A. Efeito de inseticidas aplicados em diferentes momentos, no número de puncturas de Liriomyza buidobrensis (Blanchard), em folhas de batata. $98 \mathrm{f}$. Monografia (Agronomia) - Universidade Estadual de Ponta Grossa, Ponta Grossa, 2000. 
GREGORIE. P. Los no tejidos y la proteción contra los insetos y los vírus. In: CONGRESO INTERNACIONAL DE PLÁSTICOS EN LA AGRICULTURA, 12., 1992, Francia. Actas... Francia: [s.n.]. 1992. p. 45.

HATA, T. Y. et al. Excluding pests from red ginger flowers with insecticides and pollinating, polyester, or polyethylene bags. Journal of economic entomology, River Side, v. 88, n. 2, p. 387-392, 1995.

HEMPHILL, JR. et al. Prevention of Potato Virus Y transmission in potato seed stock with direct covers. Plasticulture, Madrid, n. 79, p. 22-26, 1988.

OTTO, R. F.; GIMENEZ, C.; CASTILLA, N. Modificações microclimáticas sob proteção de polipropileno cultivado com espécies hortícolas em Córdoba, Espanha. Horticultura Brasileira, Brasília, v. 18, n. 3, p. 225-228, 2000 a.

OTTTO, R. F. et al. Eficiência do 'não tecido' de polipropileno na proteção contra danos de geada na cultura do morangueiro, no município de Ponta Grossa - PR. In: CONGRESSO BRASILEIRO DE OLERICULTURA, 40., São Pedro, SP. Resumos... São Pedro, SP: Sociedade de Olericultura do Brasil. 2000b. p. 759-760.

PARRELA, M. P. Biology of Liriomyza. Annual Review of entomology, Palo Alto, p. 32, 1987.

PEREIRA,D. I. P. et al. Controle químico da mosca minadora Liriomyza huidobrensis Blanchard, 1926 (Diptera: Agromyzidae) em batata no sul de Minas Gerais. In: CONGRESSO BRASILEIRO DE ENTOMOLOGIA, 17., 1998, Rio de Janeiro. Resumos... Rio de Janeiro: Sociedade Entomológica do Brasil, 1998. p. 373.

REGHIN, M, Y.; OTTO, R. F.; SILVA, J. B. C. "Stimulate Mo" e proteção com "tecido não tecido" no pré-enraizamento de mudas de mandioquinha-salsa. Horticultura Brasileira, Campinas, v. 18, n. 1, p.53-56, 2000.

REIS, P. R.; SOUZA, J. C. O Minador das folhas da Batata. Informe Agropecuário, Belo Horizonte, v. 20, n. 197, p.72-76, 1999.

SÁ, G. D. Efeito da proteção com tecido "não tecido" sobre o desenvolvimento e produção da alface (Lactuca sativa L.). 94 f. Monografia. (Agronomia) - Universidade Estadual de Ponta Grossa, Ponta Grossa, 1998.

SOUZA, J. C. Flutuação populacional e danos causados pela mosca-minadora Liriomyza huidobrensis Blanchard, 1926 (Diptera: Agromyzidae) em batata (Solanum tuberosum), no plantio de inverno, no sul de Minas Gerais. In: CONGRESSO BRASILEIRO DE ENTOMOLOGIA, 16., 1998, Salvador. Resumos... Salvador: Sociedade Entomológica do Brasil, 1997. p. 87-89.

WEBB, S. E.; LINDA, S. B. Evaluation of spunbonded polyethylene row covers as a method of excluding insects and viruses affecting fall-grown squash in Florida. Journal of economic entomology, Palo Alto, v. 85, n. 6, p. 2459-2466, 1992.

WELLS, O. S.; LOY, J. B. Intensive vegetable production with row covers. HortScience, Alexandria, v. 20 , n. 5 , p. $822-826.1985$.

Recebido: 23/09/2007

Received: 09/23/2007

Aprovado: $31 / 10 / 2007$

Approved: $10 / 31 / 2007$ 